\title{
Evaluation of the spread of pandemic influenza A/H1N1 2009 among Japanese university students
}

\author{
Mitsuo Uchida • Minoru Kaneko • Teruomi Tsukahara • \\ Shinsuke Washizuka $\cdot$ Shigeyuki Kawa
}

Received: 26 February 2014/ Accepted: 11 June 2014/Published online: 4 July 2014

(C) The Japanese Society for Hygiene 2014

\begin{abstract}
The pandemic influenza A/H1N1 2009 virus is commonly known to affect younger individuals. Several epidemiological studies have clarified the epidemic features of university students in Japan. In this study, we reviewed these studies in Japan in comparison with reports from other countries. The average cumulative incidence rate among university students was $9.6 \%$, with the major symptoms being cough, sore throat, and rhinorrhea. These epidemiological features were similar between Japan and other countries. Attitudes and behaviors toward pandemic influenza control measures were different before and improved during and after the epidemic. These features were also similar to those in other countries. On the other hand, the epidemic spread through club activities or social events, and transmission was attenuated after temporary closure of such groups in Japan. This transmission pattern was inconsistent among countries, which may have been due to differences in lifestyle and cultural habits. Based on these results, infection control measures of pandemic influenza for university organizations in Japan should be considered.
\end{abstract}

M. Uchida $(\bowtie) \cdot$ M. Kaneko $\cdot$ T. Tsukahara $\cdot$ S. Washizuka ·

S. Kawa

Center for Health, Safety and Environmental Management,

Shinshu University, 3-1-1 Asahi, Matsumoto, Nagano 390-8621,

Japan

e-mail: uchida01@shinshu-u.ac.jp

T. Tsukahara

Department of Preventive Medicine and Public Health, Shinshu

University School of Medicine, Nagano, Japan

S. Washizuka

Department of Psychiatry, Shinshu University School of

Medicine, Nagano, Japan
Keywords Influenza A/H1N1 $2009 \cdot$ Pandemic · Infection control · University organization · University students

\section{Introduction}

There was a major worldwide outbreak of swine-origin influenza A/H1N1 (H1N1) in 2009. This H1N1 pandemic infected approximately 20 million people and caused 198 deaths in Japan [1]. In 2013, avian influenza A/H7N9 infected humans in China and raised concern regarding the recurrence of a pandemic [2]. Therefore, the records of several H1N1 pandemics should be evaluated for construction of measures to prevent or limit the spread of such outbreaks in future.

H1N1 infected many young individuals from the beginning of the pandemic [3-6]. According to previous reports, H1N1 spread mainly among schoolchildren and students, and this phenomenon was widely observed in Japan [1], Europe [7], and the USA [8]. Moreover, a previous study of university students also indicated that H1N1 influenza spread among adolescents [9]. Therefore, in the USA, the Centers for Disease Control and Prevention (CDC) distributed H1N1 information to adolescents from the early stages of the pandemic [10]. In addition, the American College Health Association conducted surveillance of H1N1 among university students and reported its spread in real-time [11]. This information was thought to be useful for rapid implementation of adequate infection control measures at university organizations [12]. We also reported epidemiological studies among university organizations in Japan [13-16] and the results indicated that many students were infected with H1N1 and the specific transmission route was identified among university 
students in Japan. However, in Japan, although the information of H1N1 at educational organizations was distributed broadly it was not featured at universities or colleges in great detail. As specific infection control information was not distributed among universities and college organizations, this may partly have affected the spread of H1N1 among university students. Several studies have been reported and epidemic features have been clarified. Therefore, to establish infection control measures for university students for future influenza pandemics, we should evaluate the specific features of the H1N1 pandemic among university students in Japan. Moreover, outcomes in Japan should be compared with those reported in other countries and differences as well as similarities should be discussed.

Here, we present a review of previous epidemiological studies among university organizations in Japan. In addition, this study was performed to obtain useful information for the development of future pandemic influenza control measures.

\section{Literature search procedure}

The literature from April 2009 to December 2013 was searched. In the Japanese literature, we searched for reports in the Japanese medical journal database "Igaku Chuo Zasshi" using the following terms in Japanese: (H1N1 OR influenza) AND (university OR college) AND "student" AND "epidemiology." In addition, the official journal of the Japan University Health Association was also checked. After this procedure, 17 reports were selected. In addition, we searched for reports written in English on PubMed using the following terms: (H1N1 OR influenza) AND (university OR college OR school) AND "student" AND "epidemiology." After checking all of the abstracts, 15 reports from Japan and other countries along with this review were selected. All references in these reports were checked and a few reports were added. Finally, we reviewed 36 reports in this study.

\section{Descriptive epidemiology}

The authors reported a cumulative incidence rate of $8.9 \%$ among university students in Shinshu University, Japan [13]. In addition, the epidemic curve for students was quite different from those of schoolchildren and staff. Moreover, the incidence rates were 40.0 and $1.7 \%$, respectively, even within the same organization. Table 1 shows the cumulative incidence rates of university students according to several reports and the rates ranged from 5.0 to $14.3 \%$ [13, 17-23]. The $95 \%$ confidence intervals (95\% CIs) of each incidence rate were recalculated as follows: $95 \% \mathrm{CI}$ lower $=\mathrm{IR}-1.96 \times \mathrm{SE}, \quad 95 \% \mathrm{CI} \quad$ higher $=\mathrm{IR}+$ $1.96 \times \mathrm{SE}$ (IR: incidence rate, $\mathrm{IR}=$ patient number/total number of students; SE: standard error, $\mathrm{SE}=(\mathrm{IR}(1-$ IR)/total number of students $)^{1 / 2}$ ). Moreover, all of the patients and the total number of students were summed and the average rate was estimated to be 9.6 , and $95 \%$ CI was estimated to range from 3.8 to $15.4 \%$. A previous conference report [24] indicated an infection rate of $6.7 \%$ in 54 universities in Japan, and there was no remarkable disparity with this report. Moreover, freshman students had a particularly high infection rate [13, 20, 22]. This was thought to be because freshmen had closer relationships and acted less independently than upper grade students [13], and, therefore, the disease may have greater opportunities to spread. There were also H1N1 epidemiological reports regarding $\mathrm{H} 1 \mathrm{~N} 1$ infection among university organizations in other countries. Iuliano et al. [25] prepared an epidemiological report conducted at Delaware University in the early stage of the 2009 pandemic; influenza-like illness was reported by $10 \%$ of students between March and May 2009. Witkop et al. [26] reported the H1N1

Table 1 Cumulative incidence rates and $95 \%$ confidence intervals of Japanese university students

\begin{tabular}{llcrrr}
\hline Ref. no. & University & Number of patients & Total number & Incidence rate & $95 \%$ CI \\
\hline$[17]$ & Ochanomizu University & 165 & 3303 & 5.0 & 0.7 \\
{$[18]$} & Ibaraki University & 645 & 8060 & 8.0 & 2.3 \\
{$[13]$} & Shinshu University & 1016 & 11424 & 8.9 & 13.3 \\
{$[19]$} & Aichi University of Education & 389 & 4322 & 9.0 & 14.5 \\
{$[20]$} & Nagasaki University & 841 & 7489 & 11.2 & 3.3 \\
{$[21]$} & Kagawa University & 644 & 5700 & 11.3 & 5.4 \\
{$[22]$} & Kanazawa University & 924 & 7945 & 11.6 & 17.6 \\
{$[23]$} & Niimi College & 57 & 397 & 14.3 & 5.1 \\
& Total & 4681 & 48640 & 9.6 & 17.5 \\
\hline
\end{tabular}


epidemic in the US Air Force Academy and showed that the incidence rate during the outbreak period was $11 \%$. In addition, Iuliano et al. [9] also summarized the H1N1 infection rate of high school/university students as 6-10\% in US schools. Thus, the proportion of H1N1 influenza patients among university students is probably robust regardless of country.

The authors reported that $\mathrm{H} 1 \mathrm{~N} 1$ was spread through clubs, close friends, apartments, or classrooms during the epidemic period [14]. The transmission routes were investigated by interviews. University students had been instructed to report when diagnosed with $\mathrm{H} 1 \mathrm{~N} 1$ at hospital or clinics and then designated staff interviewed the students to determine probable or suspected transmission route. Because determination of the true transmission route was difficult, whenever possible, the suspected transmission source for each case was similarly checked to confirm infection. This interview method was used in the first report of the H1N1 pandemic [5] and is, therefore, thought to be appropriate. Transmission routes were investigated based on the interview method and consisted mostly of club activities [14, 17, 22] or festivals [20, 21, 27] in Japan. According to the epidemic curve described [14], both the first and second peaks mainly coincided with club activity. In club activities, students usually meet with other club members, remain in the club room for long periods, eat and drink together, and come into close contact with other club members, and, therefore, may be easily infected with H1N1. They were also infected through apartments and lodgings. If influenza was present in one lodging, the epidemic was prone to spread because many students lived together. This spread of infection was peculiar to university students and may be less prevalent in other populations. Although schoolchildren mainly transmitted H1N1 in the classroom, the rate of $\mathrm{H} 1 \mathrm{~N} 1$ transmission among university students through lectures or laboratories was lower than that through club activity in Japan [14]. H1N1 transmission through university classrooms was not regarded as the main transmission route of the epidemic in Japan. This was probably because university students generally attend lectures on different subjects and move repeatedly between classrooms. In other countries, from the viewpoint of H1N1 transmission, Guh et al. [28] investigated the students of Delaware University and found influenza-like illness risk among those who cared for an ill individual or lived with an ill housemate. The risk of transmission among housemates was high, similar to the authors' report. However, although a comparison with reports in Japan could not be performed because the category of club activity was not included, contact sports or parties did not show a high risk of transmission. It was also reported that illness risk was significantly increased by studying with an ill individual. Holmes et al. [29] investigated the geographic H1N1 transmission pattern at the University of California, San Diego, and found that transmission occurred outside the university rather than within the campus. Hence, the H1N1 transmission route may have been different among Japanese university students. On the other hand, Witkop et al. [26] reported that H1N1 was spread through large social events, similar to the observations in Japan, and they suggested that transmission occurred easily at events with gathering of large numbers of people. Thus, H1N1 transmission was not consistent among countries. This was understood to be due to differences in lifestyle (e.g., club activities or lectures) and cultural habits (e.g., parties or festivals) of university students among these studies.

\section{H1N1 natural history and clinical symptoms of university students}

Among university students, the median times from $\mathrm{H} 1 \mathrm{~N} 1$ infection to the development of fever and from the development of fever to cure were 2 and 5 days, respectively. Students visited hospitals within 1 day and were cured at 4 days after medication. In addition, median time not attending classes was 5 days [16]. These times were distributed non-parametrically. Moreover, these times were affected by environmental and individual factors, including route of infection, gender, and grade [16]. Another report showed that mean fever duration was approximately 2 days if antiviral drug was administered immediately; however, fever duration was prolonged up to 5 days if medication was delayed [21]. Thus, the fever duration was suggested to vary according to the timing of medication. From the authors' experience, clinical symptoms of H1N1 infection other than fever were cough, headache, rhinorrhea, sore throat, and arthralgia (unpublished data), and Kamano et al. [21] and Kameda et al. [22] also reported similar symptoms. From these reports, in addition to fever symptoms, cough $(75.6 \%)$ was seen in most cases followed by sore throat $(48.4 \%)$ and rhinorrhea (45.8\%) among university students, although averages were calculated only from these three records (Table 2). Similar to Japanese reports, Iuliano et al. [25] reported that clinical symptoms included sore throat $(84.3 \%)$, rhinorrhea $(84.1 \%)$, cough $(78.6 \%)$, and headache $(70.5 \%)$, although the rates of these symptoms were slightly higher. In addition, the median duration of illness was 6 days, which was also similar to that in Japan. Witkop et al. [26] reported that the clinical symptoms included cough $(93 \%)$, sore throat $(86 \%)$, and rhinorrhea $(49 \%)$. Thus, the incidence rate and clinical symptoms showed similar tendencies in these reports. This natural history and symptoms were not markedly different from those of seasonal influenza. 
Table 2 Clinical symptoms of H1N1 among Japanese university students

\begin{tabular}{|c|c|c|c|c|c|c|c|}
\hline \multirow{2}{*}{$\frac{\text { Symptom }}{\text { Cough }}$} & \multirow[t]{2}{*}{ Ref. no. } & \multirow{2}{*}{$\begin{array}{l}\text { University } \\
\text { Shinshu University }\end{array}$} & \multirow{2}{*}{$\frac{\text { Prevalence }}{725}$} & \multirow{2}{*}{$\frac{\text { Infections }}{1009}$} & \multirow{2}{*}{$\frac{\text { Rate }}{71.9}$} & \multicolumn{2}{|c|}{$95 \% \mathrm{CI}$} \\
\hline & & & & & & 63.0 & 80.7 \\
\hline & {$[21]$} & Kagawa University & 531 & 644 & 82.5 & 74.8 & 89.8 \\
\hline & {$[22]$} & Kanazawa University & 691 & 924 & 74.8 & 66.3 & 83.3 \\
\hline & & Total & 1947 & 2577 & 75.6 & 67.1 & 84.0 \\
\hline \multirow[t]{4}{*}{ Sore throat } & & Shinshu University & 336 & 1009 & 33.3 & 24.0 & 42.5 \\
\hline & {$[21]$} & Kagawa University & 380 & 644 & 59.0 & 49.4 & 68.6 \\
\hline & {$[22]$} & Kanazawa University & 531 & 924 & 57.5 & 47.8 & 67.2 \\
\hline & & Total & 1247 & 2577 & 48.4 & 38.6 & 58.2 \\
\hline \multirow[t]{4}{*}{ Rhinorrhea } & & Shinshu University & 374 & 1009 & 37.1 & 27.6 & 46.5 \\
\hline & {$[21]$} & Kagawa University & 377 & 644 & 58.5 & 48.9 & 68.2 \\
\hline & {$[22]$} & Kanazawa University & 429 & 924 & 46.4 & 36.7 & 56.2 \\
\hline & & Total & 1180 & 2577 & 45.8 & 36.0 & 55.6 \\
\hline
\end{tabular}

\section{Infection control measures at university organizations}

\section{Pharmaceutical interventions}

Yoshimura et al. [30] reported that rapid diagnosis of H1N1 was performed at university health service centers. In this report, they discussed the savings in terms of time and effort because students or staff could check for H1N1 infection immediately on the university premises. They also noted the drawback of false-negatives because of the time lag between infection and symptoms using the rapid diagnostic kit if the patient came to the health center too quickly and the center had to pay for materials. On the other hand, there were no reports of vaccinating students at university because of insufficient supplies of H1N1 vaccine in the early stages of the pandemic. However, preventive medication with antiviral drugs was performed at university health service centers [30]. Almost all patients were given antiviral drugs when students were infected and went to hospitals or clinics and were diagnosed with H1N1 [16].

If pharmaceutical interventions, including rapid diagnosis, are administered via university health service centers, the advantages (e.g., time saving) and disadvantages (e.g., costs) of the medication should be clarified [30]. On the other hand, if medication is administered outside the university, nearby clinics or hospitals should be informed of the university infection control measures to make it easier for students to receive medication at these institutions.

\section{Non-pharmaceutical interventions}

Influenza pandemic prevention measures were developed based on the Ministry of Health and Welfare's Influenza Pandemic Plan [31] and implemented at each university. Several measures, including hand washing, wearing a mask, and coughing etiquette, were posted on the university home page or sent by e-mail, and students were required to stay away from the university and go to a hospital or clinic if they felt that they may be infected with influenza [13]. These measures were also implemented in several universities in Japan [18-22, 27]. For more advanced information administration, utilization of mailing lists [20] or construction of novel web systems [32] was applied. As there are general communication systems through which all students can receive information at university in Japan, the information was announced at all universities during the period of the H1N1 epidemic. In addition, this online announcement system was also utilized in most universities in the USA [33].

Some reports indicated that the whole university was closed to prevent H1N1 transmission [34, 35]. These closures were performed especially in the early stage of the H1N1 pandemic as "proactive closure." This measure is not usually conducted to prevent seasonal influenza at universities [36]. As whole school closure was conducted and the subsequent epidemic was diminished [34, 35], this was suggested to have had an effect on preventing virus transmission, in agreement with reports before and after the H1N1 pandemic. Cuachemez et al. [37] reviewed the effects of school closure according to several previous reports that evaluated past seasonal or pandemic influenza outbreaks; they reported that closure of schools during a pandemic may have effect on the total number of cases and may reduce peak infection rates. Jackson et al. [38] reviewed reports regarding the effects of school closure during the H1N1 pandemic in 2009 and concluded that timely school closure can potentially reduce transmission during an influenza outbreak. Similarly, H1N1 was spread through club activities or social events in Japan, and these high-risk activities were canceled [14, 27]. As this partial closure resulted in the isolation of infected individuals in high-risk groups and decreased the chances of virus transmission, this measure may be effective to prevent infection when small epidemics 
continue in several groups. In the authors' previous report [14], clubs with multiple infected members were closed and subsequent epidemic was shown to be suppressed. However, evaluation of partial closure was more difficult than whole closure because transmission was influenced by environmental or individual factors. Jackson et al. [38] also suggested that the contact pattern in schools may have influenced the effects of closure measures. Hence, although these closures may suppress the transmission of influenza virus, longitudinal epidemiological studies regarding school closures should be performed to accurately evaluate the effects of such closures.

To tackle future influenza pandemics, the Cabinet Secretariat of Japan announced Special Measures to Counter New Types of Influenza [39] in May 2012, which was passed into law in April 2013 in Japan. This law was developed to clearly present evidence of pandemic influenza measures. In this law, prescribed large facilities are required to restrict human interactions in the event of an emergency period of pandemic influenza. According to the enforcement ordinance of this law, although schools are defined as "category 1" (vulnerable to influenza spread and requiring strong infection control measures), university organizations are defined as "category 3" (requiring moderate infection control measures). Therefore, university organizations may be regarded as less dangerous compared to schools. In addition, universities will not be closed fully according to this law even in the event of an influenza pandemic. However, it may be useful to implement advanced infection control measures, including proactive closures, at university organizations regardless of these categories if it is necessary to close facilities in the early period of an influenza pandemic in Japan.

\section{University students' attitudes and behaviors regarding H1N1}

To improve pandemic influenza measures, it is necessary to determine the actual attitudes and behaviors of university students regarding the H1N1 pandemic. Koike et al. [40] reported that individual preventive measures were taken at a rate of approximately $20 \%$ before the pandemic but increased to $30-50 \%$ after onset of the pandemic. According to this report, individual prevention was insufficient before the pandemic, and this may have led to the spread of the virus. Ohmi et al. [41] also reported a poor attitude of university students to preventive measures before the H1N1 pandemic, and they suggested that preventive education should be promoted among students. On the other hand, Tashiro et al. [20] investigated the individual prevention behavior among university students in each faculty before the H1N1 pandemic and reported that the proportion was higher among those in medical faculties than others. Urahashi et al. [42] also reported that more than $80 \%$ of nursing students implemented individual prevention measures. These reports indicated that attitudes or preventive behaviors regarding infection among university students were generally low before the influenza pandemic, while the proportion tended to be higher among those in medical or nursing faculties. In addition, the behavior was found to be strengthened after experiencing the pandemic. In other countries, Mitchell et al. [43] reported that $64.9 \%$ of students took some individual prevention measures during the $\mathrm{H} 1 \mathrm{~N} 1$ pandemic, and $96 \%$ of respondents to an online survey among Delaware University students answered that they had strengthened their hand washing behavior. Among respondents who reported concern, approximately $80 \%$ of students took the recommended individual protective measures. Although there was one report that the behavior of university students toward the pandemic did not change much [44], most reports, including those of Kats et al. [45] and Zottarelli et al. [46], indicated improvement of university students' behavior because of their experience with the H1N1 pandemic. It was suggested that university students tended to strengthen individual prevention measures after experiencing or becoming concerned about influenza. Thus, further preventive education before a pandemic will be required for infection control strategies.

\section{Conclusion}

We reviewed previous studies of $\mathrm{H} 1 \mathrm{~N} 1$ at university organizations in Japan and evaluated the actual state and epidemiology of the infection spread. We concluded that the cumulative incidence rate was approximately $9.6 \%$ and clinical characteristics were not different from those of seasonal influenza; the findings were approximately similar to those in other countries. In contrast, we also concluded that there were some specific features of influenza transmission in Japan that were inconsistent between countries. For future influenza pandemics, in addition to general infection control measures, specific measures according to country may further inhibit or slow the spread of infection. In Japan, raising awareness in the early stages of the epidemic, improvement of attitudes toward infection control, and not only whole closure but also temporary closure of meetings of high-risk groups of university students may be useful measures to limit spread among university students.

Acknowledgments We acknowledge all staff at the Center for Health, Safety and Environmental Management of Shinshu University. This study was partly supported by a grant from Young Scientists' Exploratory Research, Shinshu University. 
Conflict of interest None to declare.

\section{References}

1. Situation of H1N1 in Japan. 2014. http://www.mhlw.go.jp/bunya/ kenkou/kekkaku-kansenshou04/inful_surve.html. Accessed 6 Feb 2014.

2. Avian influenza $A(H 7 N 9)$ virus. 2014. http://www.who.int/influ enza/human_animal_interface/influenza_h7n9/en/index.html. Accessed 6 Feb 2014.

3. Fraser C, Donnelly CA, Cauchemez S, Hanage WP, Van Kerkhove MD, Hollingsworth TD, et al. Pandemic potential of a strain of influenza A (H1N1): early findings. Science. 2009; 324(5934):1557-61.

4. Girard MP, Tam JS, Assossou OM, Kieny MP. The 2009 A (H1N1) influenza virus pandemic: a review. Vaccine. 2010; 28(31):4895-902.

5. Lessler J, Reich NG, Cummings DA, Nair HP, Jordan HT, Thompson N. Outbreak of 2009 pandemic influenza A (H1N1) at a New York City school. N Engl J Med. 2009;361(27):2628-36.

6. Carrillo-Santisteve P, Renard-Dubois S, Cheron G, CsaszarGoutchkoff M, Lecuit M, Lortholary O, et al. 2009 pandemic influenza $\mathrm{A}(\mathrm{H} 1 \mathrm{~N} 1)$ outbreak in a complex of schools in Paris, France. Euro Surveill. 2010;15(25).

7. Amato-Gauci A, Zucs P, Snacken R, Ciancio B, Lopez V, Broberg E, et al. Surveillance trends of the 2009 influenza A(H1N1) pandemic in Europe. Euro Surveill. 2011;16(26).

8. H1N1 Flu (Swine Flu): resources for K-12 schools. 2014. http:// www.cdc.gov/h1n1flu/schools/. Accessed 6 Feb 2014.

9. Iuliano AD, Dawood FS, Silk BJ, Bhattarai A, Copeland D, Doshi S, et al. Investigating 2009 pandemic influenza A (H1N1) in US schools: what have we learned? Clin Infect Dis. 2011;52(Suppl 1):S161-7.

10. H1N1 Flu (Swine Flu): resources for colleges and universities. 2014. http://www.cdc.gov/h1n1flu/institutions/. Accessed 6 Feb 2014.

11. Influenza like illness (ILI) in colleges and universities. 2014. http://www.acha.org/ILI_Project/ILI_Surveillance.cfm. Accessed 6 Feb 2014

12. Soto Mas F, Olivarez A, Jacobson HE, Hsu CE, Miller J. Risk communication and college students: the $2009 \mathrm{H} 1 \mathrm{~N} 1$ pandemic influenza. Prev Med. 2011;52(6):473-4.

13. Uchida M, Tsukahara T, Kaneko M, Washizuka S, Kawa S. Swine-origin influenza A outbreak 2009 at Shinshu University, Japan. BMC Public Health. 2011;11:79.

14. Uchida M, Tsukahara T, Kaneko M, Washizuka S, Kawa S. How the H1N1 influenza epidemic spread among university students in Japan: experience from Shinshu University. Am J Infect Control. 2012;40(3):218-20.

15. Uchida M, Tsukahara T, Kaneko M, Washizuka S, Kawa S. Effect of short-term school closures on the H1N1 pandemic in Japan: a comparative case study. Infection. 2012;40(5):549-56.

16. Uchida M, Tsukahara $T$, Kaneko M, Washizuka S, Kawa S. Evaluation of factors affecting variations in influenza $\mathrm{A} / \mathrm{H} 1 \mathrm{~N} 1$ history in university students, Japan. J Infect Chemother. 2013;19(4):665-72.

17. Ohki S, Morita Y. Analysis of information gathered by interviews to students with a novel swine-origin influenza $\mathrm{A}(\mathrm{H} 1 \mathrm{~N} 1)$ virus illness in Ochanomizu University. Campus Health. 2011;48(2): 73-8 (in Japanese).

18. Hasegawa T, Miyakawa H, Takizawa T, Takeshita S, Yamane S, Kaneda T, et al. Preparation of an action plan against H1N1-type novel influenza and its future problems. Campus Health. 2011;48(2):67-72 (in Japanese).
19. Hisanaga N, Okada A, Aratake S, Wada K, Sakakibara Y, Kameyama $S$, et al. The epidemic of swine origin influenza H1N1 and the effects of absence of close contact workers with infection cases at X university. Iris Health. 2010;9:3-6 (in Japanese).

20. Tashiro T, Isayama Y, Kawahara K, Kuga A, Shirakawa A, Tanaka K, et al. Pandemic influenza (H1N1) 2009 in Nagasaki University students. Health Sci Res. 2011;23(2):7-14 (in Japanese).

21. Kamano H, Mori T, Murakami C, Kugoh T, Izumi C, Tomiie K, et al. Pandemic H1N1 2009 influenza in Kagawa University: clinical symptoms and the effects of oseltamivir and zanamivir. Campus Health. 2011;48(2):174-9 (in Japanese).

22. Kameda M, Yoshikawa H, Nakamura H, Miyazaki S, Tagami Y, Uchiyama K, et al. Novel influenza (H1N1) infection in Kanazawa University "The epidemic and associated transmission factors among undergraduate students". Campus Health 2011;48(2):169-73 (in Japanese).

23. Uno F. A report on influenza cases in a college during the 2009/2010 influenza (H1N1) pandemic. Bull Niimi Coll. 2010;31:29-33 (in Japanese).

24. Ishikawa T, Yamamoto $\mathrm{K}$, Baba H, Ohta T, Kamano H, Kawamura $\mathrm{T}$, et al. Actual state and infection control measure for influenza A/H1N1 2009 in National University, Japan. Campus Health. 2011;48(1):337-9 (in Japanese).

25. Iuliano AD, Reed C, Guh A, Desai M, Dee DL, Kutty P, et al. Notes from the field: outbreak of 2009 pandemic influenza A (H1N1) virus at a large public university in Delaware, April-May 2009. Clin Infect Dis. 2009;49(12):1811-20.

26. Witkop CT, Duffy MR, Macias EA, Gibbons TF, Escobar JD, Burwell KN, et al. Novel influenza A (H1N1) outbreak at the US Air Force Academy: epidemiology and viral shedding duration. Am J Prev Med. 2010;38(2):121-6.

27. Masaki Y, Fujimura N, Nakayama H, Toda M, Matsuzono M, Tanaka T, et al. Experience in and future prospects of preventing the spread of on-campus influenza infection by formulating and implementing an influenza outbreak status confirmation system. Campus Health. 2011;48(2):121-6 (in Japanese).

28. Guh A, Reed C, Gould LH, Kutty P, Iuliano D, Mitchell T, et al. Transmission of 2009 pandemic influenza A (H1N1) at a Public University-Delaware, April-May 2009. Clin Infect Dis. 2011;52(Suppl 1):S131-7.

29. Holmes EC, Ghedin E, Halpin RA, Stockwell TB, Zhang XQ, Fleming R, et al. Extensive geographical mixing of 2009 human H1N1 influenza A virus in a single university community. J Virol. 2011;85(14):6923-9.

30. Yoshimura A, Musashi M, Narabe M, Orito C, Sato M, Kaneko T. Rapid diagnostic testing for influenza in health administration center, Hokkaido University. Campus Health. 2010;47(2):133-8 (in Japanese).

31. A guideline for Influenza A(H1N1). 2014. http://www.mhlw.go. jp/bunya/kenkou/kekkaku-kansenshou04/09.html. Accessed 6 Feb 2014.

32. Tanaka Y, Matsumoto K, Fujii K, Kunegi Y, Kosaka M, Shibuya $\mathrm{M}$, et al. Infectious disease management that used WEB-based reporting system in the university. Campus Health. 2011;48(2): 43-8 (in Japanese).

33. Schwartz RD, Bayles BR. US university response to H1N1: a study of access to online preparedness and response information. Am J Infect Control. 2012;40(2):170-4.

34. Nakagawa K, Kusuda S, Katayama H, Yokouchi K, Nakajima M, Tsuchiya S, et al. A criterion of school closure, and surveillance system: from the experience of 2009 novel influenza A (H1N1) in Ritsumeikan University. Campus Health. 2010;47(2):91-6 (in Japanese).

35. Sakaguchi M, Tobitani W, Kawaguchi S, Nakatsuka T. Risk management of new type influenza (A/H1N1) in Osaka Kyoiku 
University. Mem Osaka Kyoiku Univ. 2010;59(1):31-42 (in Japanese).

36. Uchida M, Kaneko M, Yamamoto H, Honda T, Kawa S. Effects of school closure during influenza A/H1N1 pandemic in 2009 in Japan. Nihon Eiseigaku Zasshi. 2013;68(2):103-17 (in Japanese).

37. Cauchemez S, Ferguson NM, Wachtel C, Tegnell A, Saour G, Duncan B, et al. Closure of schools during an influenza pandemic. Lancet Infect Dis. 2009;9(8):473-81.

38. Jackson C, Vynnycky E, Hawker J, Olowokure B, Mangtani P. School closures and influenza: systematic review of epidemiological studies. BMJ Open 2013;3(2).

39. Special measures to counter new types of Influenza. 2014. http:// www.cas.go.jp/jp/influenza/120511houritu.html. Accessed 6 Feb 2014.

40. Koike I, Sekizuka N, Oda H, Kido T. The change in preventive action for swine influenza and its affecting factors in university students. Hokuriku J Public Health. 2010;37(1):12-6 (in Japanese).

41. Ohmi H, Funane H, Yuki Y, Harimoto K, Terayama K. An attitude survey of influenza A/H1N1 among citizens and university students: a comparison with online survey. Hokkaido J Public Health. 2010;23(2):80-5 (in Japanese).
42. Urahashi K, Shiroki Y, Araki A, Kumagai H, Kanoda H, Yamagishi $\mathrm{C}$. Health behavior that nursing university students execute at new influenza A (H1N1) pandemics. Bull Coll Nurs Ibaraki Christ Univ. 2010;2(1):49-54 (in Japanese).

43. Mitchell T, Dee DL, Phares CR, Lipman HB, Gould LH, Kutty P, et al. Non-pharmaceutical interventions during an outbreak of 2009 pandemic influenza A (H1N1) virus infection at a large public university, April-May 2009. Clin Infect Dis. 2011;52(Suppl 1):S138-45.

44. Van D, McLaws ML, Crimmins J, MacIntyre CR, Seale H. University life and pandemic influenza: attitudes and intended behaviour of staff and students towards pandemic (H1N1) 2009. BMC Public Health. 2010;10:130.

45. Katz R, May L, Sanza M, Johnston L, Petinaux B. H1N1 preventive health behaviors in a university setting. J Am Coll Health. 2012;60(1):46-56.

46. Zottarelli LK, Sunil TS, Flott P, Karbhari S. College student adoption of non-pharmaceutical interventions during the 2009 H1N1 influenza pandemic: a study of two Texas universities in Fall 2009. Prev Med. 2012;55(5):497-9. 